\title{
MANAGEMENT OF A RESTORED ARCHITECTURAL HERITAGE: THE VILLA FICANA ECOMUSEUM (ITALY)
}

\author{
A. P. Conti ${ }^{1, *}$ \\ ${ }^{1}$ Architect - apconti57@gmail.com
}

Commission II - WG II/8

KEY WORDS: Raw Earth Architecture, Cultural Work, Memory, Social Ties, Cultural Associations, Young Volunteers, Ecomuseum

\begin{abstract}
:
Ficana, the area of raw earth houses built in the 19th century in the town of Macerata, is an example of vernacular architecture. About ten years ago it was restored. The restoration work - ordered by the Municipality - concerned half of the about fifty houses that make up the neighbourhood. The restored houses have been used for some years by local associations for cultural activities. Recently, after a public competition, the nine houses belonging to the municipality were granted, free of charge, to a group of cultural associations in order to create an Ecomuseum. The Villa Ficana Ecomuseum of raw earth houses was initiated in May 2016. Currently, the activity is dedicated to the implementation of initiatives aimed at rediscovering and enhancing local culture and memory. The inhabitants of Ficana and the entire citizenship are involved in the initiatives. Another field of action for the Ecomuseum is the study and enhancement of the constructive technique of raw earth building. This activity is aimed at professionals, owners and all those involved in green building and sustainable development. An important aspect of the Ecomuseum's activity is the fact that management work is carried out by young volunteers: young people engaged in the experience of the European and National Community Service. This also makes a fruitful exchange between local and European realities possible.
\end{abstract}

\section{VILLA FICANA}

\subsection{Historical evolution}

In 2006, Ficana, the area of raw earth houses in Macerata, was revamped. We have, here, a real example of urban regeneration whose positive repercussions have gone well beyond the technical results achieved and regard the social aspect of the area too. Ficana comes into being in the mid-nineteenth century, on the outskirts of the town, as a small, rural hamlet. (Anselmi, Volpe, 1987) In its entirety, it consists of approximately 50 houses made of earth - known locally as atterrati - built in rows, consisting of two storeys and very small in size (Saracco, 2002).

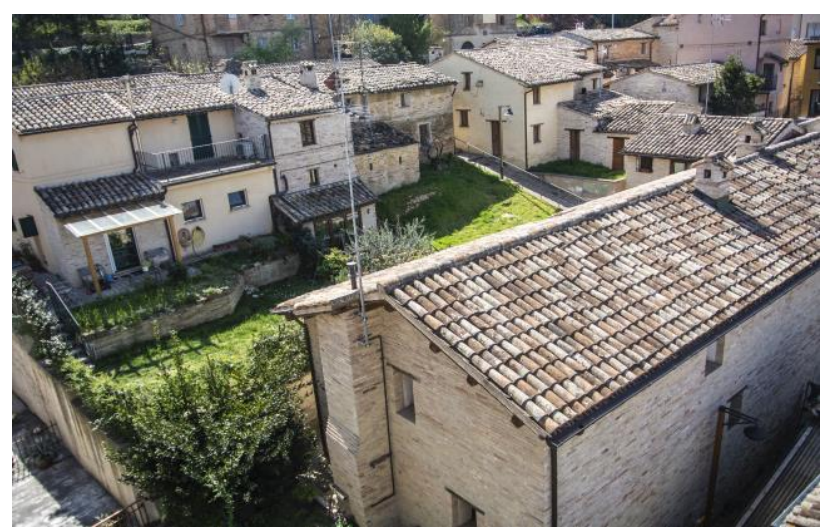

Figure 1. Villa Ficana.

It is a place lived in by people on the fringes of society - initially by those people who have moved from the countryside to the town, country farmers and workers without a steady income, in recent years by immigrants. For this reason, it has acquired a nonpositive reputation.
Despite this poor reputation, the area is given life by a cohesive community which shares memories carried on throughout the generations (Palombarini, Volpe, 2002). It remained lively till the post-WWII period, when "progress" determined its abandon and decay. People are ashamed of living in Ficana, in such squalid houses, and especially, in houses made of raw earth. Official Building Control in the 1970s envisaged demolition in order to provide space for modern condominium buildings, one of which was carried through to completion. The earth houses seemed to be condemned inevitably.

The rebirth of the area was only possible if the general consideration that went with it changed. A long and slow job began aiming at reconciling these houses with the common feeling of the people of Macerata; both the houses' particular qualities and the value of the area had to be highlighted.

\section{THE REBIRTH}

\subsection{Cultural redevelopment}

The first phase is the cultural redevelopment carried out from the beginning of the early 90s. The commitment of Schools, both at Primary (Scuola Elementare Fratelli Cervi, 1998) and Secondary levels, of the University [The Academy of Fine Arts (Marcaccio, 2007)], and of cultural associations [FAI - Fondo Ambiente Italiano] has been of great significance. The work was aimed both at training young people and at enhancing the local heritage. The activity was diversified in relation to the age of children and the nature of the different educational institutions. The students, thanks to the collaboration of experts, learned of the vernacular architecture and in particular of the raw architecture, investigated its history, typology and technology.

\footnotetext{
Corresponding author
} 
Practical workshops were also created in which students could freely manipulate the earth but also test the traditional local building system (massone/cob) and the creation of plaster or meaningful artistic artefacts. This work allowed the town to understand the importance of this small rural hamlet as well as its unique quality and the value of earth architecture. Such initiatives received the fundamental support of the State. In 2003, the Authority for Architecture and Landscaping for the Marche Region - at the end of a procedure implemented in agreement with the Municipality of Macerata - subjected the area to landscape constraints in accordance with D. Lgs. (Legislative decree) $\mathrm{N}^{\circ}$. 490/99, underlining the historical value of Ficana (Salvati, 2005).

At the end of 2004 a new Rescue Plan ${ }^{2}$ for the area was adopted. Following the Plan every atterrato has been studied and described using historical plans, detailed drawings and photographs that showed the current condition. Ficana district was then, and is now, officially recognized as an important historical site, placed under the direct protection of Macerata Municipality and of the Italian State. Later, in 2005/2006, the Local Authorities directly began a restoration project - which includes approximately half of these atterrati houses in this area of town, some of which were of public property - all respecting Rescue Plan rules and use of traditional technologies. Such work was partially financed by a Marche Region Call for Tenders aiming to safeguard these raw earth houses. The work constituted an important test bed for recovering a building technique using earth - the cob - for a long time abandoned and nearly lost ${ }^{3}$.

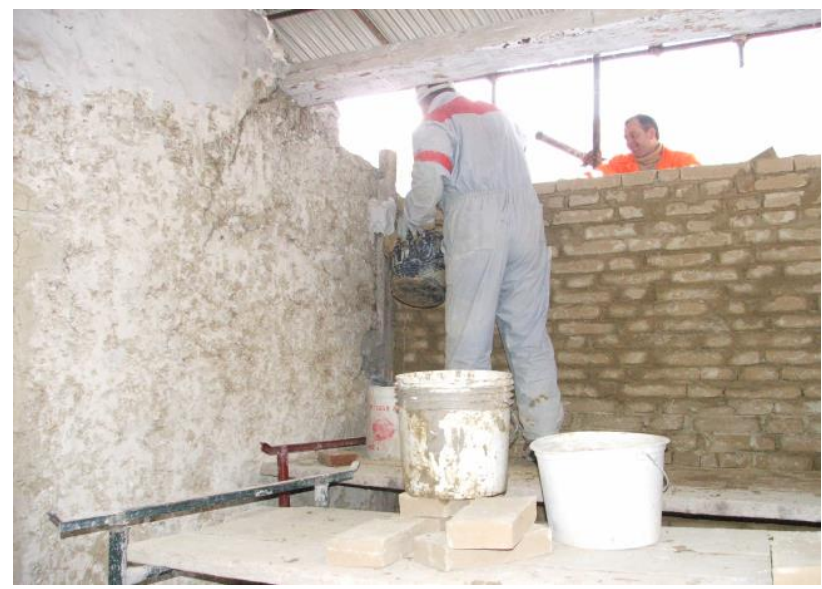

Figure 2. The restoration work.

The atterrati generally were not in good condition, but only three - out of thirteen - were seriously damaged and only one was destroyed. The technique mainly used was cob but there were also adobe wall portions. The most important damage was caused by the rain that washed away and damaged the walls, when the roofs were not in good condition. Insignificant damage was caused by a seismic event (the earthquake in1997) or by the moisture of the soil. The restoration work, in accordance with the prescription of the Rescue Plan, was executed "... using earth for the restoration and repairing of walls ... using the same technology in the same place".

Since in the Marche the massone technique was no longer used, before beginning the work it had been necessary to start experimental work finalized to testing the ancient massone technology and to actualizing it.
The restoration was a conservative work, so the peculiarity of each atterrato was respected. The materials used were only: earth, straw, sand, wood, lime and bricks for the baseboards, no concrete was used. Massone was used for little repairs and adobe where large rebuilding was necessary. The collapsed building was rebuilt using adobe walls (Conti, 2009). The most important outcome of the work is, however, the change we can see at the end of it all, in the mentality of the Macerata people, towards that town area and buildings in raw earth. Following the physical renewal, people are rediscovering Ficana, undertaking deeds of redevelopment for those buildings not-yet revamped and are returning to live in those old houses again and today the atterrati are nearly all inhabited again. Yet more importantly, social ties, torn apart due to decay and abandonment are slowly, but surely, coming together again. Raw earth is no longer associated with misery and backwardness, but with the ideas of sustainable building, saving resources and living comfort too.

Following revamping in 2015, after a period where the atterrati were used by cultural associations, in agreement with the goals of regional funding, the Municipal Authorities published a call for competition promoting a "museum-like" initiative with the aim of enhancing the hamlet. The GRUCA ONLUS Association in partnership with other local associations and together with the Associazione Internazionale Città della Terra Cruda, presented a project which proposed using some of the raw earth buildings belonging to the local Authority as an Ecomuseum. Nine buildings were involved, five of which were directly destined to exhibitions and didactic activities - within them simple life scenes have been recreated or spaces for teaching purposes have been built - and four to guest the young members of the European Volunteer Service, one of the activities run by GRUCA ONLUS, collaborating with the Servizio Civile Nazionale. Participation in the European project allowed for the birth of the Ecomuseum of the Villa Ficana raw earth houses in 2016.

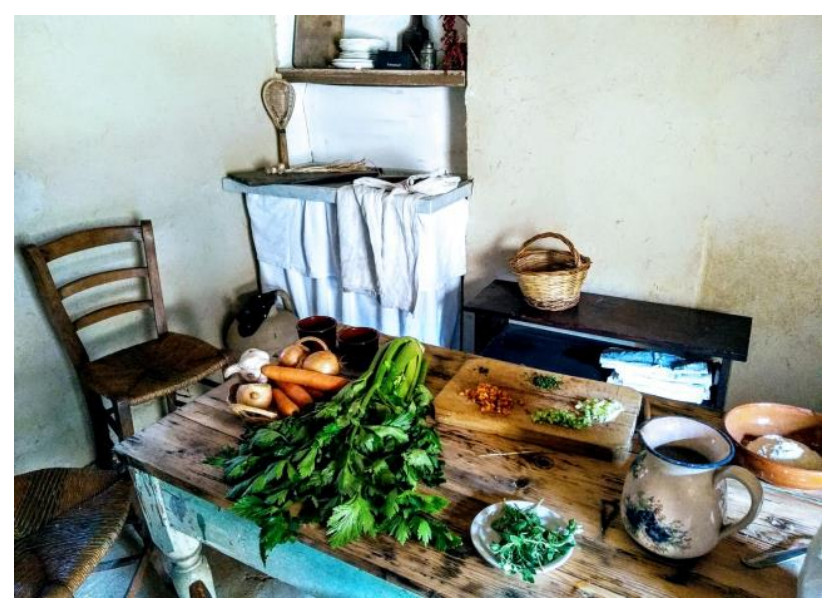

Figure 3. The kitchen of the Ecomuseum.

This has been possible because the use, free of charge, of the atterrati set aside by the Municipality consented spending part of the funds destined to the project for the hospitality of the volunteers who keep the Ecomuseum up and running. The volunteers welcome visitors and manage the Ecomuseum. There are four Italian volunteers and four from other European countries, and they contribute with their work in making the area alive, bringing - together with their enthusiasm - the experience of where they come from. 
The volunteers are trained and put into contact with vernacular architecture. They learn the architectural and technical characteristics of both the hamlet and the raw earth material. They also learn the potential uses of raw earth for new construction within the field of sustainable architecture. All this favours dissemination of knowledge on a supranational level.

\subsection{Urban regeneration}

The act of urban regeneration carried on over the years makes people, spontaneously, go back to live in the area of Ficana again. The presence of the Ecomuseum, the initiatives undertaken (e.g. photographic portraits of the inhabitants, collaboration with ICLeS - Istituto per la Clinica dei Legami Sociali - Institute for Studies on Social Ties - Higher Institute in Psychotherapy), the role of young volunteers' motivational activities and services aid the spontaneous rebirth of the community providing the stimulus for the reconstruction of social ties. Meetings are organised to which the inhabitants are invited. Mutual knowledge and sharing are stimulated. The inhabitants acquire awareness of the particularity of the place they have chosen to live in and this increases the sense of belonging. The activity of enhancing local culture takes advantage of the precious collaboration of the few old inhabitants who really and truly represent the memory of the area, able to make a precious heritage of traditions emerge.

Today the Ecomuseum can be considered a cultural incubator designed to: sensitise the young local population to the recovery of its historical identity; support the enhancement of the ecosustainable construction method; increase social and aggregative activities; promote cultural activities in the city; create specific educational workshops with the handling of raw earth; propose study activities (conferences, meetings and technical seminars) and animation of the territory with guided tours and theatrical narratives.

The positive effect may be valued in relation to the rest of Macerata too. Its people culturally repossess Ficana, a good characterised by a strong identity value - for years abandoned and left to decay. Economic effects also begin to show up, for example with the setting up of micro hospitality activities and local produce. Collaborations are underway with artisans and merchants to promote typical products. This appears consistent with the aim of enhancing the local culture which over the centuries has been able to create foods and objects that meet the basic needs of life while respecting the resources of the area. Cultural interest, created on both local and national levels, constitutes the starting point for a tourist activity - still in its initial phase - that may well involve the whole town of Macerata.

\subsection{The Ecomuseum}

Collaboration with the Local Authorities is important, they promote the Ecomuseum experience inserting it within the range of what the town offers as regards cultural activities. This makes it easier to reach an ever-greater number of people. All this allows giving life to communication activities which help spread good practices and upright lifestyles.

The thematic fields within which the experience of Villa Ficana can be placed span from art and psychology to the promotion of the whole surrounding area, to the purely technical field. At the core of all is the interest for the community. Some recent activities:

- Atterrati! Call for Art: Exhibition for works (photography, sculpture, painting, design) of contemporary artists coming from all over Italy and abroad.
- Grand Tour della Cultura (Cultural Grand Tour): An initiative proposed by the Councillor for Culture of the Regional Authority - themed guided tours, readings of local writers, traditional food tastings, story-telling through which we animate and relive places.

- Raw earth workshops for both adults and children: Didactic and creative activities for the rediscovery of earth as building material.

- Ficana on the Frontline: Festival through the streets of the village with entertainment, guided tours, local food tasting, sustainable and zero-km produce.

- Come have a coffee with us: Enhance the real cultural heritage of the area, the people, via a story in images where the characters live in Ficana. Pictures that simply gather up their life, a normality which belongs to us all but that maintains and conserves that area spirit which represents the soul of the place.

- Village at play: Games to understand the value of rules as well as being together, in collaboration with ICLeS Higher Institute in Psychotherapy, Macerata)

- Museum of everything and for everybody: In order to favour accessibility to the visually impaired, the whole amount of material conserved in the Visitors' Centre is completely available to touch. Besides, the Ecomuseum sets out tours in braille format as well as guided tours via app.

- Madam Butterfly: New experimental theatrical interpretation theatrical experience by professional and amateur actors in Ecomuseum spaces.

- \#InvadiFicana: Discovery of raw earth houses and of those who lived there, within the framework of the Invasioni digitali (Digital invasions) national project.

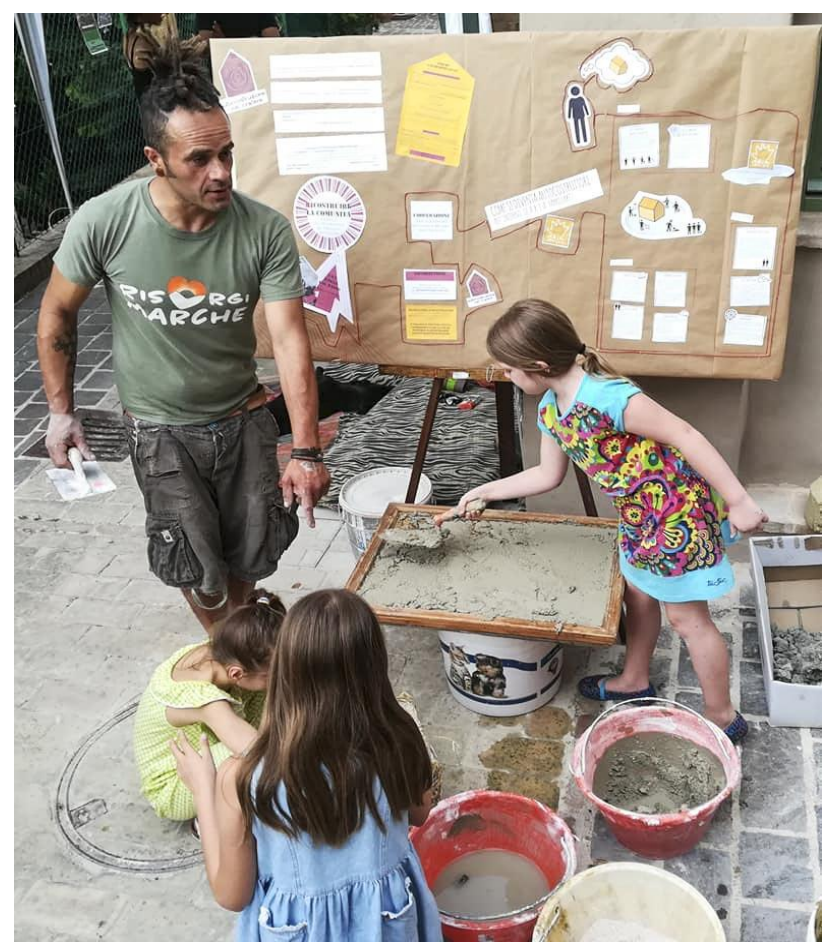

Figure 4. The raw earth workshop. 
The Ecomuseum is an Institute dealing with studying, protecting and making a community collective memory and its historical and current relationship with the area environmental resources known. Consistently with such ends, the activities proposed in Macerata are aimed at adding value to local culture but also at reinforcing social ties among new inhabitants of the area. Within the national and international panorama of the Ecomuseums, Ficana claims a particular position. The on-going experience is interesting since it allows testing the capability of an activity like that of the Ecomuseum to compare itself with the themes generated by its inclusion into an advanced urban community that has to face such issues as inclusion, the capacity of recreating social ties, innovation challenges within the field of sustainable development.

\subsection{Data-collection centre}

The Villa Ficana raw earth houses Ecomuseum is also a museum of the raw earth building tradition. Indeed, the Ecomuseum, besides promoting local resources is a centre for study, data collection and spreading information about the use of earth in architecture. Thanks to collaboration with the International Association of Raw Earth Cities, it runs a data-collection centre, in both paper and digital formats, dedicated to this specific technology. It provides synergies with local national and international bodies and represents a reference point for whoever wishes to treat this particular building technique both from the historical, scientific and technical viewpoints.

The action plan is precisely guided by recognition of the cultural value of Ficana - see the reasons behind the granting of landscape constraints - and by the understanding of the strength and vitality of its identity matrix. Consistently with the profound attention demonstrated, especially within the building sector, to those themes relating to sustainable development and energy saving, the Ecomuseum acts as Data-Collection Centre and reference point for everybody who, at a national and international level, deals with raw earth construction and sustainable architecture. In this sense, the very same physical structure of the buildings lends itself to be read as a case study both of restoring by way of an old technology abandoned for decades and of using an old technique for modern buildings. This, moreover, constitutes an example of spreading good practices. Membership of the Association, consistently with what is included in the Statute, furthermore, facilitates contacts and exchanges, commercial ones too, among the various Raw Earth Cities (Macerata joined in 2016). The Ecomuseum of Villa Ficana raw earth houses regularly organises meetings and conferences on the theme of raw earth building as well as on topics related to it and proposes to provide refresher training courses for all technical personnel.

\section{CONCLUSIONS}

The experiment implemented at Ficana may be included among the great number of those that, in Italy and in the world, try to remedy situations of abandonment and decay which too often involve different parts of the territory. It is the demonstration that through cultural work, synergy among institutions, public authorities and citizens' own initiative, interesting outcomes may be reached, and useful services may be provided. Especially, capable of letting the local communities rediscover their own roots and their own potential. Repair and rebuilding of the hamlet of Villa Ficana and the creation of the Ecomuseum respond to a plurality of objectives aimed at socio-cultural redevelopment, safeguarding, planning and sustainable management of the landscape.
Some objectives are fully achieved, others will be achieved over a longer period. These are:

- making the community aware of the strong identity and socio-cultural value of the rural landscape to which it belongs;

- encouraging the collection of tangible and intangible documents, to start specialised study and research activities;

- promoting the landscape and vernacular architecture in a European and international cultural exchange respecting their own work, behavioural and intimate traditions;

- safeguarding the cultural heritage by reintegrating the neighbourhood into the social and administrative life of the town;

- rediscovering and using past building techniques in ecosustainable terms by offering housing opportunities reformulated in a dimension of particular liveability and proximity, a new contemporary way of living to promote and spread the culture of sustainable living and improve the quality of life;

- recognising the Ecomuseum, as a dispenser of new forms of urban life, as an instrument of generational continuity, of enhancement of collective memory and local traditions through activities of animation and relationship with the surrounding neighbourhood;

- offering schools world opportunities for learning and direct experimentation through the manipulation of raw earth with particular attention for the disabled;

- experimenting with forms of tourism connected to vernacular architecture, raw earth and sustainable architecture as a possible promotional flywheel of the Ecomuseum.

The activities did not stop with the tragic seismic events of 2016/2017 which, notwithstanding the alleged fragility of raw earth buildings, did not cause any damage to the hamlet.

\section{REFERENCES}

Anselmi S., Volpe G. 1987: L'architettura popolare in Italia Marche, Laterza, Bari.

Conti A.P. in Galdieri E. 2009: Scritti sulla terra, Il prato, Padova

Marcaccio P. in Conti A.P. 2007: L'atterrato di Contrada Fontevannazza a Treia I saperi ritrovati Edicom, Udine

Palombarini A., Volpe G., 2002: La casa di terra nelle Marche Federico Motta Editore, Milano.

Salvati P. in Ministero per i Beni e le Attività Culturali, Direzione Regionale per i Beni Culturali e Paesaggistici delle Marche 2005: Architetture di terra nelle Marche, Recanati (MC).

Saracco M. 2002: Architettura in terra cruda. Il caso delle Marche, Alinea, Firenze.

Scuola Elementare Fratelli Cervi 1998: Dalla terra la casa: il Borgo di Villa Ficana, Macerata. 